[CONTRIBUTIONS FROM THE HAVEMEYER LABORATORIES OF COLUMBIA UNIVERSITY, No. 20.]

\title{
SOME NEW TELLURIUM COMPOUNDS.
}

BY VICTOR LENHER.

Received January 27,1900 .

I $\mathrm{N}$ many points tellurium resembles selenium in its derivatives, the oxides are not unlike in their behavior, and the tellurites and tellurates are very similar to the corresponding selenites and selenates.

Tellurium, owing to its high atomic weight, shows greater stability in its higher halogen derivatives than the preceding members of the group to which it belongs. Two series of halides are known, corresponding to $\mathrm{TeX}_{2}$ and $\mathrm{TeX}_{4}$. The tetrahalides are those most commonly met with and seem to be the type which tellurium tends to follow with the halogens. With selenium, on the contrary, we find the lower halides are the more stable. Heat transforms the tetra-into the monohalides with corresponding loss of halogen.

As in the case of the other natural groups of elements, the basic property is found to increase with the rise in atomic weight, so here also we find the same tendency in the higher members to be more basic than the lower ones. Sulphur is a decidedly acid element; in selenium this property is decidedly weaker, while with tellurium we actually find such salts as the tartrate, basic sulphate, and basic nitrate, which are not known in the case of a true non-metal. In appearance, tellurium resembles a metal, while sulphur and selenium, in the elementary condition, certainly do not appear metallic.

As a result of this increase in basic properties, we should expect to find that tellurium forms better defined double halides than selenium. This is actually the case. Only the double bromides of selenium are known. Attempts to prepare double chlorides thus far have proved unsuccessful, and likewise the formation of double bromides of selenium is restricted within certain limits.

It has been shown by the author that selenium tetrabromide can unite with the hydrobromides of the organic amines to form

1 This Jourtla1, 20, 572 . 
well-defined double salts in which the amine plays the rôle of ammonia in the compound $\left(\mathrm{NH}_{4}\right)_{2} \mathrm{SeBr}_{6}$. Norris ${ }^{1}$ has also prepared a number of the double halides of selenium.

When tellurium replaces selenitum in the double halides, we obtain more clearly defined compounds than is the case with the latter. In fact, while selenium tetrabromide unites with only the hydrobromides of the fatty amines and with the hydrobromides of pyridine and piperidine, no compound could be prepared with any of the true aromatic amines or with quinoline; neither has it been possible to prepare an aromatic or aliphatic amine salt in which selenium tetrachloride replaces the tetrabromide.

Both tellurium tetrabromide and tetrachloride form a series of beautiful salts with the aliphatic amines, and both of the halides also unite with the aromatic amines to form well-defined derivatives. In the series of salts which has been prepared, it is somewhat striking to notice that all the bromides are red while the chlorides are invariably yellow. Wheeler has shown that the double chlorides of tellurium with potassium, rubidium, and cesium are yellow while the corresponding bromides are red.

To prepare the salts it is only necessary to add a solution of tellurium dioxide in hydrochloric or hydrobromic acid to the amine salt dissolved in the corresponding acid; a precipitate of the double salt generally forms immediately, and this precipitate, when recrystallized from dilute acid, gives crystals of the salt in a purified condition.

All the double salts are decomposed by pure water with the formation of hydrated $\mathrm{TeO}_{2}$, but are soluble in dilute acids and in alcohol.

Method of Analysis. - Great difficulty was at first experienced in making an analysis of these compounds, owing to the complications which invariably ensued. The method which was finally adopted consisted in dissolving a weighed quantity of the salt in a dilute solution of tartaric acid, adding to this a measured excess of standard silver nitrate and a few drops of ferric alum. The solution was then treated with a standard solution of ammonium thiocyanate. The object of the tartaric acid was

1 Am. Chem. J., 20, 490.

2 Ztschr. anorg. Chem., 3, 428. 
to hold in solution the tellurium dioxide, which otherwise would be precipitated by the water, and to prevent the formation of a precipitate of silver tellurite which would interfere with the titration. When a sufficient quantity of tartaric acid is present to hold tellurium dioxide in solution and prevent its action on the silver, the method proves very accurate. The silver nitrate solution was made up of such strength that $\mathrm{I} c c .=$ 0.007969 gram bromine or 0.003533 gram chlorine.

Methylamine Bromotellurate, $\left(\mathrm{CH}_{3} \mathrm{NH}_{3}\right)_{2}{ }^{2} \mathrm{TeBr}_{6}$. - To a solution of methylamine in hydrobromic acid, a hydrobromic acid solution of $\mathrm{TeO}_{2}$ was added, when a red precipitate immediately formed. This was collected on a filter and the salt purified by recrystallization from dilute hydrobromic acid.

0.3023 gram salt required 27 . I cc. silver nitrate solution.

$$
\begin{aligned}
& \text { Calculated for } \\
& \left(\mathrm{CH}_{3} \mathrm{NH}_{3}\right)_{2} \mathrm{TeBr}_{8} \text {. Found. } \\
& \mathrm{Br} \ldots \ldots \ldots \ldots \ldots \ldots \ldots+7 \mathrm{I}, 5 \mathrm{O} \ldots \ldots
\end{aligned}
$$

The crystals are of a red color and are regular octahedrons, having a high index of refraction.

Methylamine Chlorotellurate, $\left(\mathrm{CH}_{3} \mathrm{NH}_{3}\right)_{2} \mathrm{TeCl}_{8}$.-.This substance was prepared in a manner similar to the preceding; that is, a hydrochloric acid solution of tellurium dioxide was added to a solution of the amine in hydrochloric acid and the product recrystallized from dilute hydrochloric acid.

0.3029 gram salt required $44.9 \mathrm{cc}$. silver nitrate solution.

$$
\begin{aligned}
& \text { Calculated for } \\
& \left(\mathrm{CH}_{3} \mathrm{NH}_{3}\right)_{2} \mathrm{TeCl}_{6} \text {. Found. } \\
& \text { C } 1 \ldots \ldots \ldots \ldots \ldots \ldots \ldots \ldots 5^{2.67} \\
& 52.37
\end{aligned}
$$

The crystals appear as yellow hexagonal plates, with a micaceous cleavage. The index of refraction is low, and in polarized light a low order of colors is shown.

Ethylamine Bromotellurate, $\left(\mathrm{C}_{2} \mathrm{H}_{5} \mathrm{NH}_{3}\right)_{2} \mathrm{TeBr}_{6}$. - Exactly the same procedure was adopted in the preparation of this salt as with the methylamine derivative.

0.3056 gram salt required $26.3 \mathrm{cc}$. silver nitrate solution.

$$
\begin{aligned}
& \text { Calculated for } \\
& \left(\mathrm{C}_{2} \mathrm{H}_{6} \mathrm{NH}_{9}\right)_{2} \mathrm{TeBr}_{6} \text {. Found. } \\
& \text { Br................6.6.6.6. } 68 \\
& 68.58
\end{aligned}
$$

The crystals are red hexagonal plates which show a strong 
basal cleavage. In polarized light the colors are of a low order, and the refractive index is fairly high.

Ethylamine Chlorotellurate, $\left(\mathrm{C}_{2} \mathrm{H}_{6} \mathrm{NH}_{3}\right)_{3} \mathrm{TeCl}_{6}$.-This salt forms yellow hexagonal plates showing a strong cleavage, and in polarized light showing a low order of colors.

0.3034 gram salt required 42 . I cc. silver nitrate solution.

$\begin{array}{cc}\substack{C a 1 c u l a t e d \\\left(C_{2} \mathrm{H}_{3} \mathrm{NH}_{3}\right)_{2} \mathrm{TeCl}_{6} .} & \text { Found. } \\ \mathrm{Cl} \ldots \ldots \ldots \ldots \ldots \ldots+49.24 & 49.02\end{array}$

Trimethylamine Bromotellurate, $\left[\left(\mathrm{CH}_{3}\right)_{3} \mathrm{NH}_{3} \mathrm{TeCl}_{6}\right.$. -This salt is the most strongly crystalline of all the compounds prepared. It forms red orthorhombic crystals which have a fairly high index of refraction. The crystals show a low order of colors in polarized light, but in convergent light a biaxial figure is readily seen.

0.3029 gram salt required $24.9 \mathrm{cc}$. silver nitrate solution.

$$
\begin{array}{cc}
\begin{array}{c}
\text { Calculated for } \\
{\left[\left(\mathrm{CH}_{3}\right)_{3} \mathrm{NH}\right]_{8} \mathrm{TeB} \mathrm{Te}_{6} .}
\end{array} & \text { Found. } \\
\mathrm{Br} \ldots \ldots \ldots \ldots \ldots \ldots \ldots 65.98 & 65.5 \mathrm{I}
\end{array}
$$

Aniline Bromotellurate, $\left(\mathrm{C}_{8} \mathrm{H}_{8} \mathrm{NH}_{8}\right)_{2} \mathrm{TeBr}_{8}$. - The action of the bromide of tellurium on aniline hydrobromide is quite unlike that of selenium tetrabromide. In the case of selenium, no compound seems to be formed, the aniline actually reducing the bromide of selenium even in acid solution.

When a solution of tellurium dioxide in hydrobromic acid is added to aniline hydrobromide, a red precipitate forms, which can be purified by recrystallization from dilute hydrobromic acid. The salt then appears as red monoclinic tablets which act strongly on polarized light.

0.3053 gram salt required $23.3 \mathrm{cc}$. silver nitrate solution.

$$
\begin{aligned}
& \text { Calculated for } \\
& \left(\mathrm{C}_{8} \mathrm{H}_{5} \mathrm{NH}_{3}\right)_{2} \mathrm{TeBr}_{6} \text {. Found. } \\
& \text { Br................6. } 60.34 \quad 60.82
\end{aligned}
$$

Aniline Chlorotellurate, $\left(\mathrm{C}_{6} \mathrm{H}_{5} \mathrm{NH}_{3}\right)_{2} \mathrm{TeCl}_{6}$ - - While selenium tetrabromide does not enter into combination with aniline hydrobromide, tellurium tetrabromide as has been seen, readily forms a double salt. The formation of double chlorides with selenium remains yet to be shown, while here we have the first example of the union of tellurium tetrachloride with the salt of an aro- 
matic amine. This salt, which was prepared in a manner similar to the preceding is, like all of the chlorides, yellow in color. The crystals of the salt were too small to determine their form, but they are active to polarized light. The salt is very light and feathery.

0.3017 gram salt required $34.2 \mathrm{cc}$. silver nitrate solution.

$$
\begin{aligned}
& \text { Calculated for } \\
& \left(\mathrm{C}_{6} \mathrm{H}_{3} \mathrm{NH}_{3}\right)_{2} \mathrm{TeCl}_{6} \text {. Found } \\
& \text { C1 ............... 40.25 } 40.04
\end{aligned}
$$

Pyridine Bromotellurate, $\left(\mathrm{C}_{5} \mathrm{H}_{5} \mathrm{NH}\right)_{2} \mathrm{TeBr}_{6}$. - This compound forms fine red crystals, not large enough to determine the crystallographic system of the salt, but it was found to be active to polarized light.

0.304 I gram salt required 24. I co. silver nitrate solution.

$$
\begin{aligned}
& \text { Calculated for } \\
& \left(\mathrm{C}_{5} \mathrm{H}_{5} \mathrm{NH}\right)_{2} \mathrm{TeBr}_{6} \text {. Found } \\
& \text { Br...............6. 62.55 } 63.15
\end{aligned}
$$

Pyridine Chlorotellurate, $\left(\mathrm{C}_{5} \mathrm{H}_{5} \mathrm{NH}\right)_{2} \mathrm{TeCl}_{6}$. This salt forms yellow isometric crystals having a low index of refraction. The crystals were very small.

0.3012 gram salt required $36.2 \mathrm{cc}$. silver nitrate solution.

$$
\begin{aligned}
& \begin{array}{l}
\text { Calculated for. } \\
\left(\mathrm{C}_{3} \mathrm{H}_{5} \mathrm{NH}\right)_{2} \mathrm{TeCl}_{3} \text {. Found. }
\end{array} \\
& \mathrm{C} 1 \ldots \ldots \ldots \ldots \ldots \ldots \ldots+42.54 \quad 42.46
\end{aligned}
$$

Quinoline Bromotellurate, $\left(\mathrm{C}_{8} \mathrm{H}_{7} \mathrm{NH}\right)_{2}{ }^{\top} \mathrm{TeBr}_{6}$ - -Very small red crystals of the salt were obtained, which were found to act on polarized light.

0.3026 gram salt required 2 I. $00 \mathrm{cc}$. silver nitrate solution.

$$
\begin{aligned}
& \begin{array}{l}
\text { Calculated for } \\
\left(\mathrm{C}_{9} \mathrm{H}_{7} \mathrm{TH}\right)_{2} \mathrm{TeBr}_{9} \text {. Found. }
\end{array} \\
& \mathrm{Br} \ldots \ldots \ldots \ldots \ldots \ldots \ldots \ldots \ldots+35.32
\end{aligned}
$$

Quinoline Chlorotellurate, $\left(\mathrm{C}_{9} \mathrm{H}_{7} \mathrm{NH}\right)_{2}{ }^{2} \mathrm{TeCl}_{6}$. - The crystals of this salt were also very small and were active to polarized light.

0.305 I gram salt required $30.6 \mathrm{cc}$. silver nitrate solution.

$$
\begin{aligned}
& \begin{array}{l}
\text { Calculated for } \\
\left(C_{9} \mathrm{H}_{7} \mathrm{NH}\right)_{2} \mathrm{TCCI}_{6}
\end{array} \\
& \text { Cl................. } 35.44 \quad 35.43
\end{aligned}
$$

It thus appears that both the tetrachloride and tetrabromide of tellurium readily form double salts with the salts of both the fatty and the aromatic amines. The salts crystallize well, 
and their color seems to be dependent on the halogen content, the bromides being invariably red, and the chlorides yellow.

A solution of tellurium dioxide in halogen acids gives a precipitate with nearly all of the alkaloids, probably forming salts similar to those above described. The alkaloid derivatives are now being studied in this laboratory.

\title{
THE ACTION OF $\alpha$-ACYLATED PHENYLHYDRAZINES ON THE C HLORINE DERIVATIVES OF QUINONES.
}

\author{
(PRELIMINARY REPORT.) \\ BY WiLliam MCPherson aNd ROBERT Fischer. \\ Received Jenuary $29,1900$.
}

THE investigations of $Z$ incke' on the interaction of phenyl$\alpha$-naphthoquinone, $\beta$-naphthoquinone, and phenanthraquinone condense in a normal manner with phenylhydrazine, but that under similar conditions, all of the quinones of the benzene series give hydroquinones, the reaction being attended with gas evolution. Many subsequent efforts have been made to effect a normal condensation between benzoquinone and phenylhydrazine, since this reaction would help to solve the problem of the constitution of the oxyazo-bodies. Although this has not as yet been accomplished, it has been shown by one of us $^{2}$ that the unsymmetrical acylated phenylhydrazines, e.g., $\mathrm{C}_{8} \mathrm{H}_{8} \mathrm{~N} . \mathrm{C}_{7} \mathrm{H}_{6} \mathrm{O} . \mathrm{NH}_{2}$, condense with benzoquinone in a normal manner forming a hydrazone derivative in accordance with the following equation :

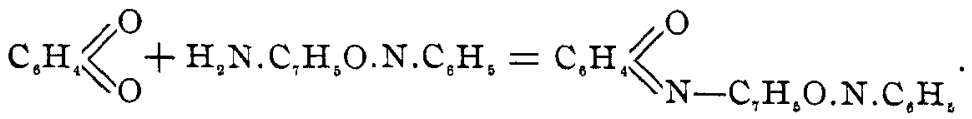

This reaction has recently been extended to the chlorine derivatives of quinone. It has been found, however, that while the $\alpha$-acylphenylhydrazines react with these readily, the compounds formed are not hydrazones but hydrazino derivatives, possessing a structure similar to the so-called anilidoquinones, formed by the interaction of quinones and aniline under certain conditions. With trichlorbenzoquinone the following reaction

1 Ber. d. chem. Ges., 16, 1563.

2 Ibid., 28, 2414;Am. Chem.J., 22, 364 . 